\title{
Door-to-Door Mobility: Evaluating a Bus Rapid Transit Community Transport Concept
}

\author{
Matthew Pahs, Minnesota Department of Transportation \\ Mark Rohden, Tri-Met \\ David Hampsten, City of Portland, Oregon Department of Transportation \\ Seth Gallant, Paratransit Services \\ Robert L. Bertini, Portland State University
}

\begin{abstract}
Portland, Oregon's regional government, Metro, has designated specific communities in outer Southeast Portland as areas that should be planned to accommodate future population growth. Both Metro and the Tri-County Metropolitan Transportation District of Oregon (Tri-Met) have expressed a desire for Bus Rapid Transit (BRT) service to this area from downtown Portland, within a corridor approximately following Southeast Powell Boulevard and Foster Road.

A preliminary analysis of BRT alignment alternatives was completed for this study. After six possible alignment options linking downtown Portland with Pleasant Valley and Damascus Town Centers were identified, a multivariate corridor analysis was applied to each option. Criteria used to select the best alignment alternative included regional connectivity, local ridership, operational costs, trip duration, distance, right-of-way and political feasibility, environmental costs, and capital costs. In addition, recommendations have been made for possible station locations along the preferred alternative corridor.

This analysis is intended to assist Tri-Met in its efforts to begin planning, designing, and implementing a BRT system in this area. The results of the analysis suggest that
\end{abstract}


a BRT system is feasible for the Powell/Interstate 205/Foster alignment. The outcome also suggests that BRT has the capacity to influence land use and could generate high transit ridership. Overall, it is recommended that Tri-Met and Metro continue to evaluate opportunities for BRT in this alignment.

\section{Introduction}

For many people, buses have become a last resort transportation choice due to their apparent reputation as an undesirable, poorly performing mode. However, as traffic congestion increases and light rail transit (LRT) construction costs escalate, many transit properties have begun to take advantage of technological advances and new concepts in vehicle design and corridor development.

BRT combines qualities of fixed-guideway transit with the flexibility of traditional bus systems. A BRT system can use both general traffic lanes and/or dedicated guideways, smooth-riding vehicles, improved station amenities, and Intelligent Transportation Systems (ITS) technology to enhance the performance of the system and encourage higher transit usage. By combining attributes of rail and bus systems, BRT can achieve the benefits of both. The purpose of this corridor analysis is to evaluate and prioritize BRT elements that are responsive to community needs and the expected travel demand in Portland, Oregon's Southeast corridor.

\section{Purpose and Need}

The Portland region is delimited by an urban growth boundary (UGB), which designates urban and rural lands. Metro has projected Southeast Portland as one area for growth (see Figure 1). In particular, the communities of Pleasant Valley and Damascus are projected to grow in population from 13,000 to 125,000 residents by 2020 (Metro 2000). Infrastructure is currently lacking and transit service does not exist in these areas. Metro's Regional Transportation Plan (RTP) has identified several potential BRT corridors for future study and development, including the Powell-Foster corridor extending from Portland's downtown to Pleasant Valley and Damascus. Consistent with regional planning policies, it is likely that development will be concentrated in town centers and along major transportation routes. Implementing a BRT system in this corridor would anticipate growth and demand for travel to downtown Portland, build a 


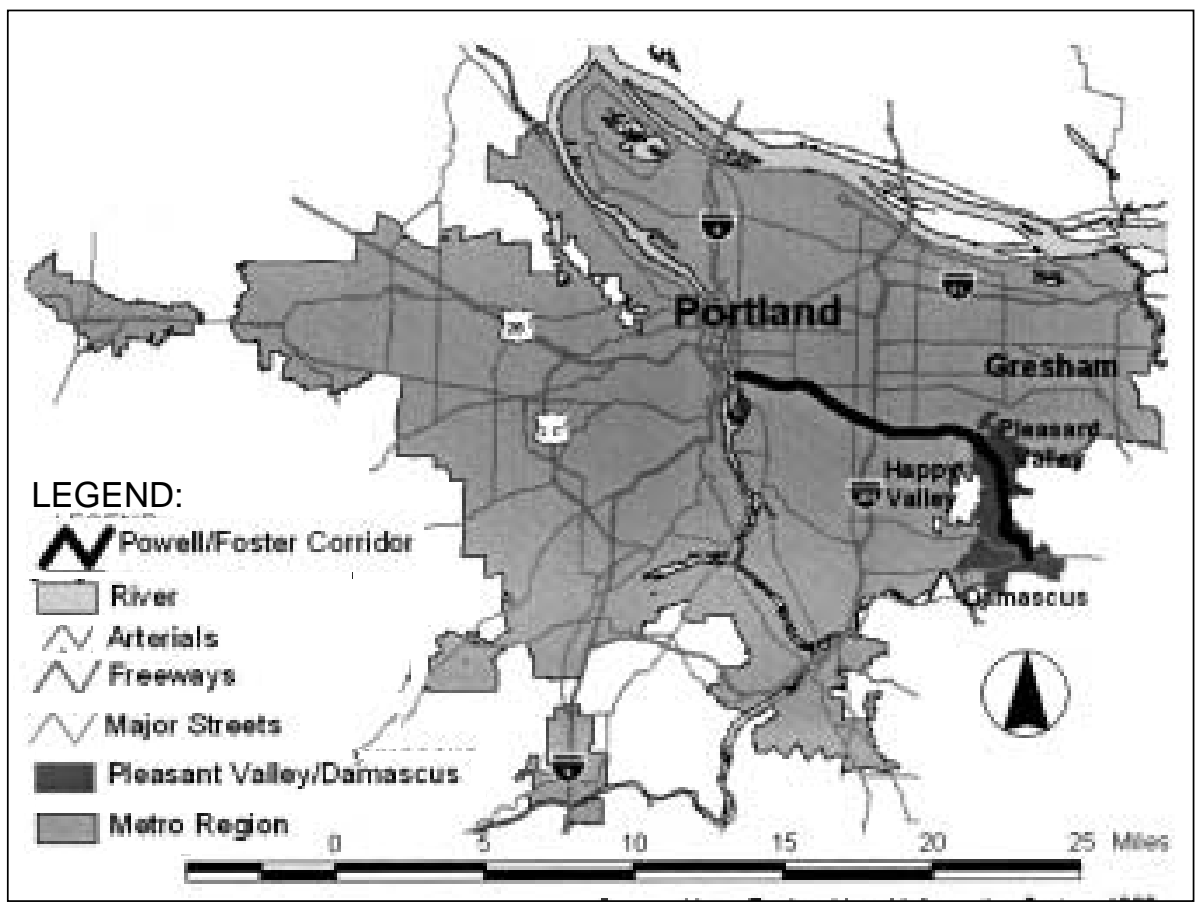

Source: Metro Regional Land Information System. 1999.

Figure 1 Regional context

transit constituency, and provide an opportunity to proactively influence future growth and create transit-oriented communities (TOCs).

\section{Door-to-Door Mobility Concept}

The cumulative effects of traffic congestion, traffic signals, number of stops, and passenger boardings and alightings add to total transit travel time, affecting on-time performance and ridership. Buses typically travel in mixed traffic on established roadways and tend to lack visibility and attractiveness, constituency, and a sense of permanence in an urban setting. Portland Door-to-Door Mobility (PDM) will integrate visible amenities, such as high-capacity stations and articulated vehicles, to create a transit system that will attract new riders. Moreover, the concept will provide single-seat rides to downtown Portland and seamless transfers to the existing transit network. 


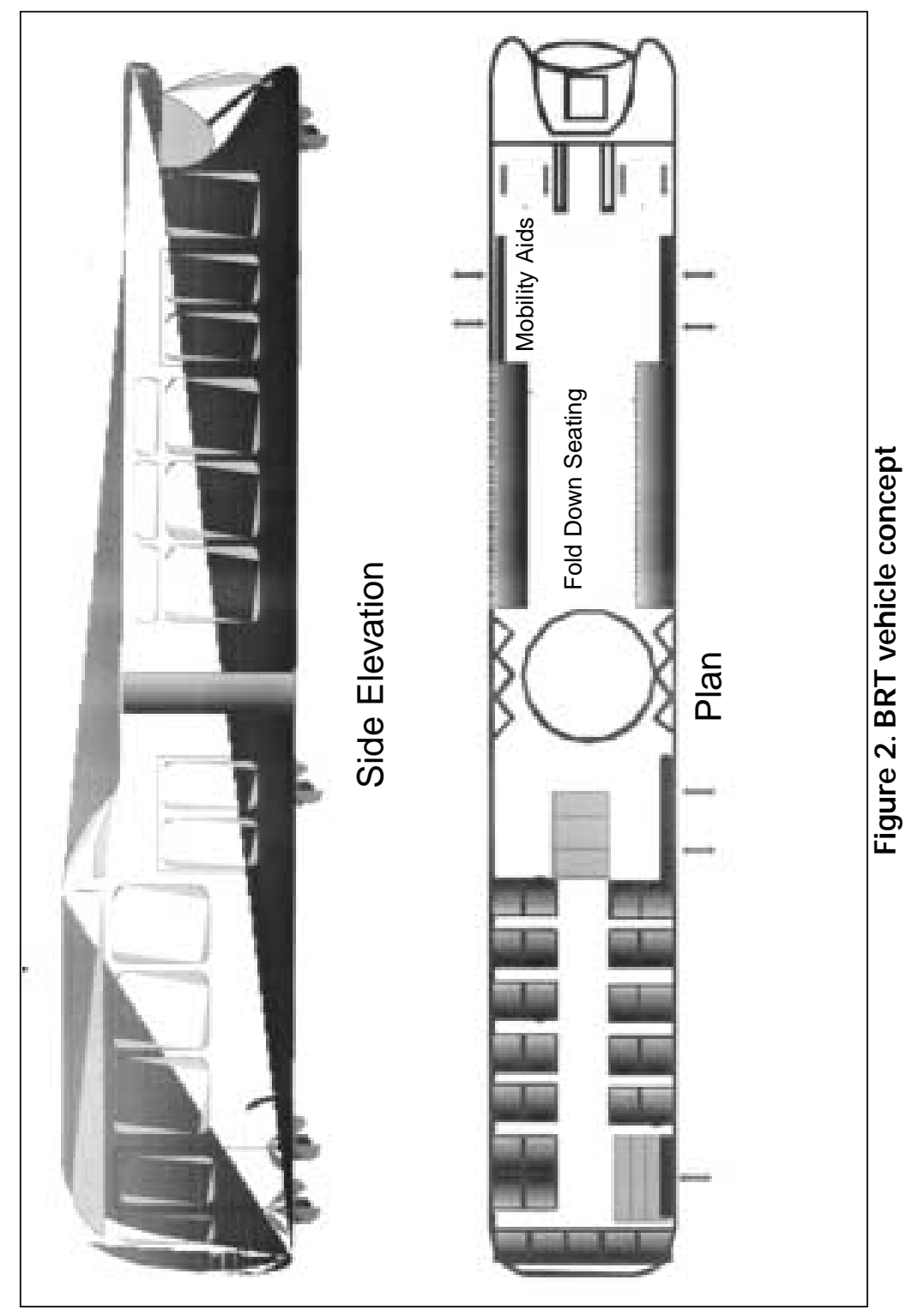




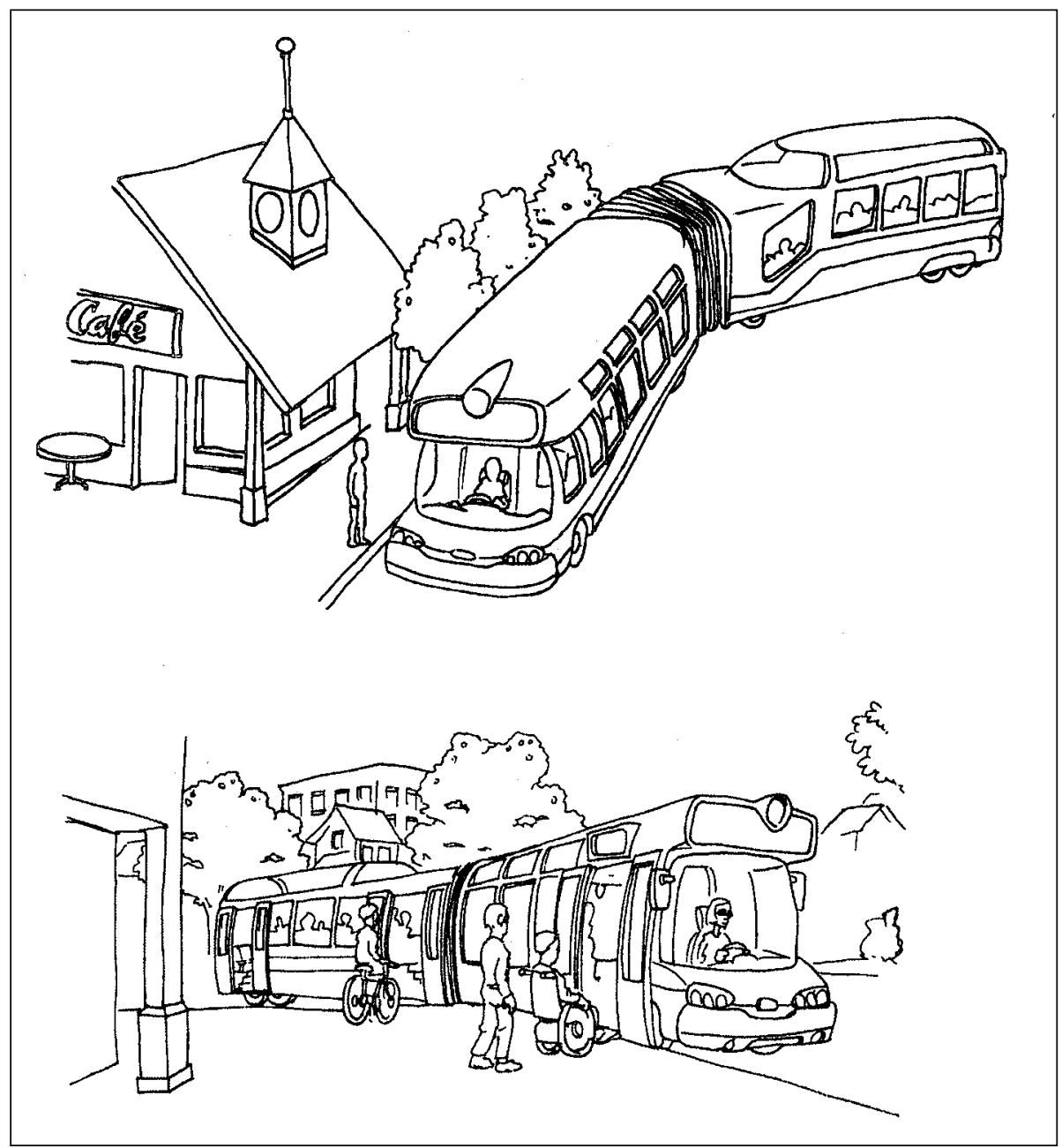

Figure 3. Vehicle concept

\section{Innovative Vehicle Design}

PDM vehicles (Figures 2 and 3) will promote a highly desirable form of transit and distinguish the system from the local bus service. Using an innovative design and bright colors, along with large windows and wide doors, the articulated vehicles will be attractive to both choice riders and potential new riders. Wide doors on both sides allow for simultaneous boarding and alighting, which will facilitate passenger movement and minimize dwell times. The vehicles' low-floor 
design provides level boarding to all customers, including people using mobility aids. As shown in Figure 2, the seating arrangement includes forward- and rear-facing seats, individual foldout tables, and flip-down side-facing seats in the front section of the vehicle. Bicycles can be stored out of the way on wall or ceiling mounts. In addition, Americans with Disabilities Act (ADA) requirements will be met by accommodations for up to two wheelchair units in the front section of the vehicle.

\section{Intelligent Transportation Systems}

The PDM concept vehicle will be equipped with advanced voice and data communication technologies and an automatic vehicle location (AVL) system using Global Positioning Systems (GPS) for fleet management and for providing real-time information to all customers. A transit signal priority system will also use real-time vehicle information to predict vehicle arrival times, determine whether that vehicle is on schedule, and provide either an extension of the green phase or a truncation of the red phase.

\section{Guideway}

The PDM system will incorporate a guideway where possible, allowing the vehicle to travel safely at high speeds without increasing the width of the travel lanes. Guideways are permanent investments in infrastructure, providing a fixed route for the vehicles, which enables the system to influence land uses, encourage transit-oriented developments (TODs), and promote ridership. The guideway will also allow vehicles to arrive at stations with longitudinal and lateral precision, increasing the efficiency and safety for all patrons, particularly those who use mobility aids. Typical street cross sections for this BRT system are shown in Figure 4.

\section{Propulsion System}

The PDM concept vehicle has been developed with a propulsion system that employs emerging technologies including fuel cells and microturbines, for a fully regenerative hybrid engine (see Figure 5). The vehicle is powered by a natural gas-fueled, high-speed microturbine/generator. An in-wheel, inverter-controlled, three-phase axial-flux, permanent-magnet motor supplies power to the vehicle's wheels. Excess energy from the generator produces hydrogen from water in a 


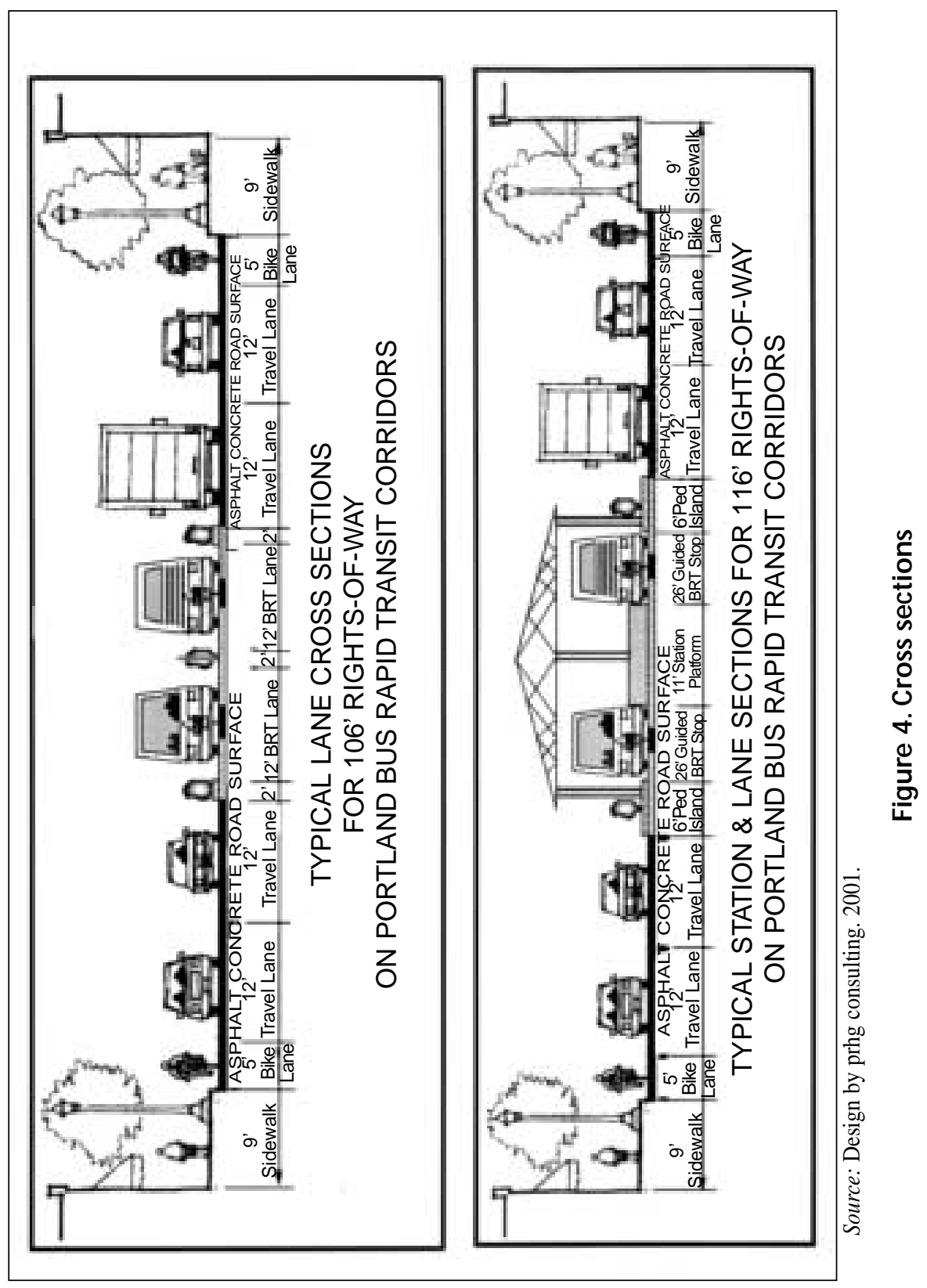




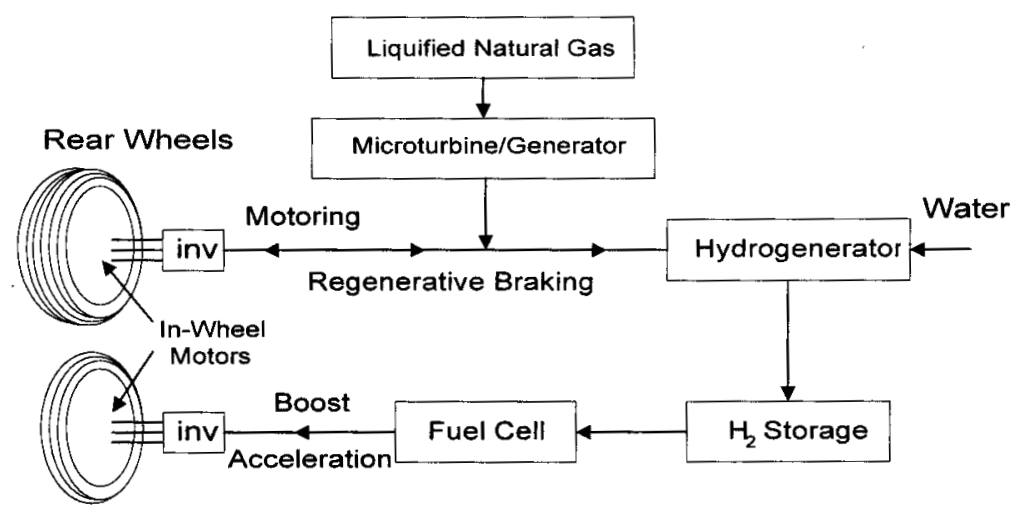

Front Wheels

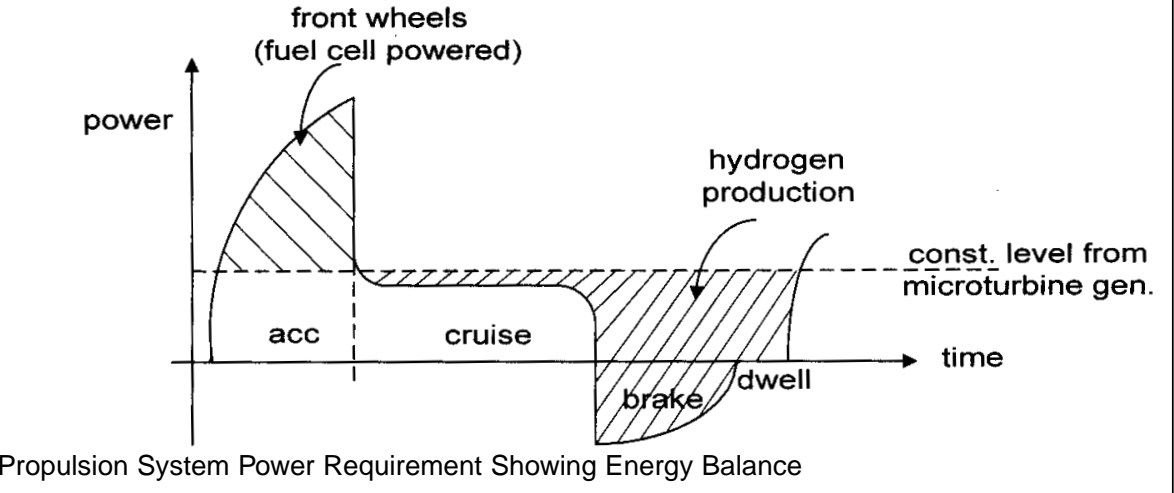

Figure 5. Sustainable propulsion system

hydrogenerator (advanced electrolysis process), which is stored for the fuel cell. Energy from the cell powers the front wheels to provide additional grade-climbing ability or boost acceleration as necessary. The vehicle's braking system is regenerative into the hydrogenerator to complete the process.

The propulsion system will be fueled by clean-burning, liquefied natural gas. This will be burned in a low-mass, high-speed microturbine operating at constant speed and power for maximum efficiency. During acceleration, all of the output of the microturbine generator will go to the rear wheels; the front wheels will be driven via power from the fuel cell. During cruise, there will be no power supplied to the front wheels. In this case, surplus energy from the microturbine generator 
will be used to produce hydrogen by electrolysis. During deceleration, the braking effort of the rear wheels will increase the level of hydrogen production. Clean and quiet vehicles will establish a positive image for BRT and will set it apart from conventional city buses.

\section{Accessibility and Mobility}

The PDM approach to accessibility issues is comprehensive. People with disabilities will have two areas on the vehicle that will automatically secure them and their mobility aids (Figure 1). Standing passengers will be provided handles and seat rests on internal sections. Both the front and rear areas of the vehicle will be equipped with real-time passenger information systems, providing both audio and visual communications. Real-time information systems will interface with personal electronic devices (e.g., personal digital assistants, cellular phones) for commuters who wish to download a schedule or route map. The vehicle is also equipped to support personal wireless communication systems for those who need to access the Internet during their trip. Station platforms will match the vehicle's door level, making boarding trouble-free and efficient for all passengers. Platforms will also include shelters to protect passengers from the elements and include electronic kiosks providing schedule information. Kiosks will also house the fare system, which will allow passengers to prepay for their trip using a smart card to ease boarding and alighting.

\section{Community BRT System}

The PDM system will be integrated with Tri-Met's transit operations in the surrounding area and will also include its own neighborhood feeder service for underserved areas of the community. Stations will be developed as community assets, where amenities may include car sharing, neighborhood electric vehicles, or electric bicycle rentals, each of which will provide local connections for residents. Pedestrian and bicycle access to the PDM system will be a priority, as encouraging these two modes will have a positive impact on ridership. Stations will become neighborhood focal points, with opportunities for retail, package delivery, cafes, and community centers of all kinds.

\section{BRT in Southeast Portland}

Implementation of BRT in the Southeast Powell-Foster corridor poses several challenges. In some areas, existing arterials have insufficient cross sections 
necessary for providing an exclusive right-of-way for BRT. In addition, general traffic flow must be maintained and local parking and air quality impacts must be minimized. BRT could help create livable TOCs and encourage transit ridership concurrent with the expected population growth in metropolitan Portland. Components of a BRT system in Southeast Portland would include some or all of the following:

- Exclusive guideway/lanes: A lane on an urban arterial reserved for the exclusive use of BRT.

- Transit signal priority: Extension of green time or actuation of signal upon detection of an approaching BRT vehicle.

- Traffic management improvements: Low-cost infrastructure elements to increase the speed and reliability of BRT service (e.g., signage, curb extensions).

- Faster boarding: Prepaid automatic fare collection systems at stations allow passengers to board easily and help facilitate quick boarding.

- Integration of transit development with land-use policy: BRT and compact TOD support one another, use less land, and encourage creation of neighborhood centers.

- Improved facilities and amenities: The advantages of separating BRT from traffic can be complemented with improved amenities such as shelters, stations, and real-time schedule data [Federal Transit Administration (FTA) 2000].

\section{Analysis}

This analysis is an adaptation of a process designed to elicit responses from stakeholders, whereby those individuals are asked to judge the importance of certain criteria in making transportation policy decisions. This corridor study includes the evaluation of six possible BRT alignments using a list of criteria and an initial study of potential station locations. In this case, the authors assessed the importance and value of the criteria. 
Each alignment alternative originates in the transit mall in downtown Portland and terminates at the Pleasant Valley and Damascus Town Centers (Figure 1). According to the FTA, a BRT system should consider the following criteria:

1 transit travel-time savings and ridership increases;

2. impacts on open spaces, wetlands, and historic resources;

3. compatibility with land-use policies and contribution to economic development; and

4. the cost-effectiveness of the project (FTA 2000).

This study attempts to adhere to these considerations where applicable.

\section{Alignment Options}

The original alignment considered for this analysis was the Powell/Foster route to Damascus. The primary constraints associated with this particular option are two bottlenecks on Foster Road: one on Foster between 50th Avenue and Interstate 205; the second on Foster near 162nd Avenue and Jenne Road. These right-of-way constraints led to the consideration of five additional options (see Figure 6), including:

1. Powell/Interstate 205/Foster option: Avoids narrow section of Foster from 50th to Interstate 205; uses wide right-of-way on Powell between 50th and Interstate 205; then joins freeway, using dedicated lane, and heads south, rejoining Foster.

2. McLoughlin/Sunnyside and McLoughlin/Highway 212 options: Uses proposed South Corridor down McLoughlin Boulevard from downtown Portland to Clackamas Regional Center, avoiding the bottleneck on Foster Road at 162nd; proceeding along Sunnyside Road or Highway 212 to the Pleasant Valley/Damascus area. Several studies for this route are currently being assembled, most notably by Tri-Met and Clackamas County. However, no final decisions or funding for such projects has been forthcoming. 
3. Powell/Interstate 205/Sunnyside and Powell/Foster/Interstate 205/Sunnyside options: Uses Interstate 205's generous right-of-way. The two alternatives using this general route are nearly identical except that the former follows Powell all the way to the freeway, while the latter leaves Powell at 50th and follows Foster to the freeway. Despite appearing indirect, these were chosen because they avoided environmentally sensitive areas in Pleasant Valley and because they connect to the Clackamas Regional Center.

4. Powell/Division/182nd option: Uses Powell until Interstate 205, heads briefly north on Interstate 205, and turns east on Division Street, with a very wide right-of-way to Gresham, turning south on 182 nd to Pleasant Valley/Damascus.

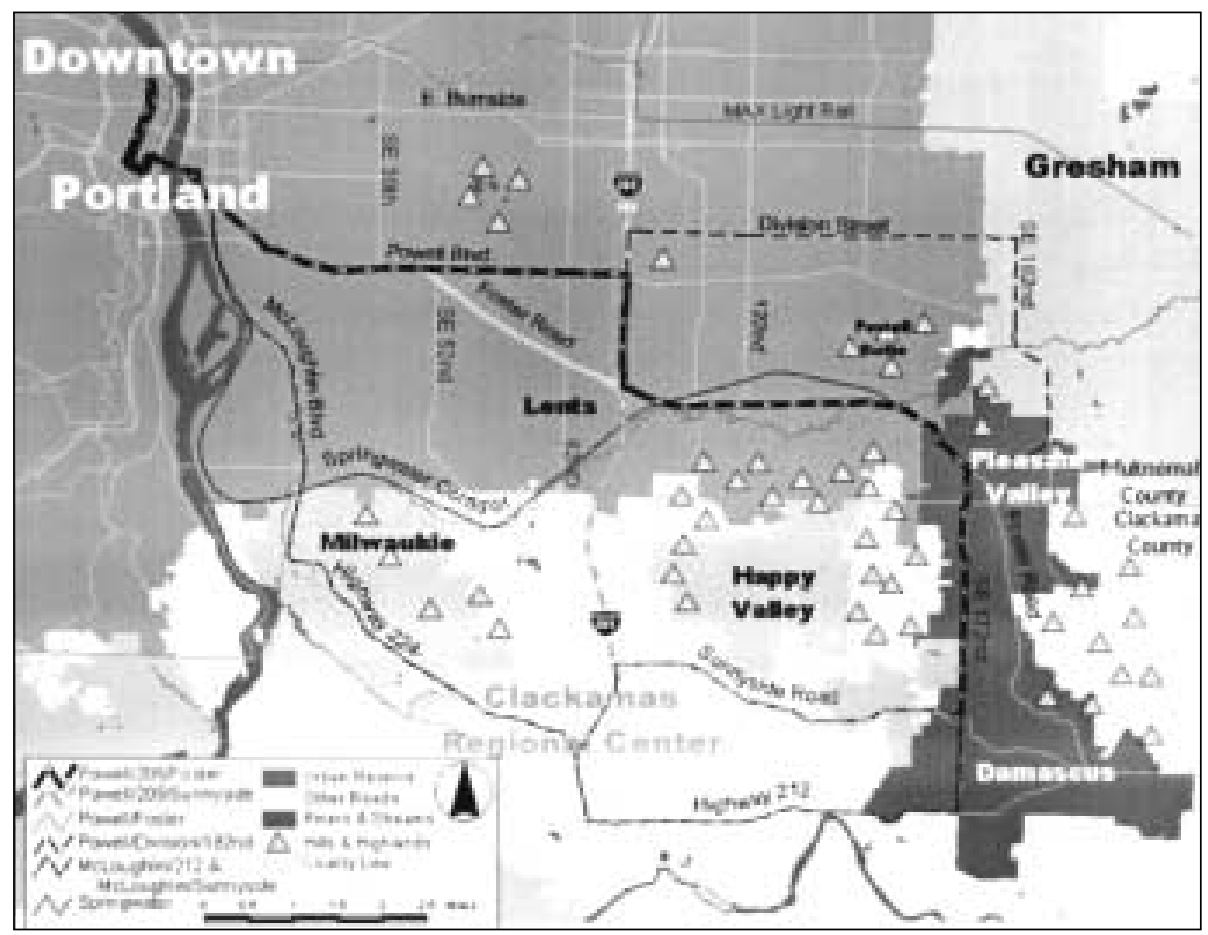

Figure 6. Alignment alternatives 
5. Springwater Corridor option: Former railroad right-of-way (100 feet wide), now a recreational trail that joins with Foster Road near Lents Town Center. Despite potential opposition, the wide right-of-way may provide valuable comparison with other alignment alternatives.

\section{Corridor Analysis}

Several conditions were developed to assess the relative merits of each alignment, and each criterion was weighted based on its relative importance. The final score for each criterion was rated on a percentage scale and was weighted and totaled. An explanation of the criteria and their respective meanings follows.

\section{Regional Connectivity (25\% Weight)}

The connectivity score was determined by estimating the presence and relative importance of activity centers and trip generators along each alignment. These included retail and employment centers, schools, colleges, and hospitals. Major activity centers were then located and geo-coded in a Geographic Information System (GIS). The trip-generation capacity of each activity node was qualitatively estimated based on empirical data and several interviews with transportation professionals. Node scores were then compiled and divided by the entire length of the route to generate a preliminary connectivity score for each corridor alignment.

\section{Local Ridership (23\% Weight)}

To estimate current ridership on each corridor, the population for each segment was multiplied by corresponding ridership rates [determined by a spatial sampling of 1998 Census tract populations (Metro 2000) within one-quarter mile of each segment] divided by the total daily transit boardings. Ridership rates for remaining corridor segments were interpolated based on density and Euclidean distance from downtown Portland. Using Metro data projecting metropolitan growth rates from 1990 to 2010 (Gresham 1999), the projected 2020 population for each segment was estimated. The total local ridership score was calculated by compiling the respective ridership populations for all segments and dividing this total by the route mileage.

\section{Operations (26\% Weight)}

This variable includes estimated travel time for each option, number of sharp turns the vehicle must make, number of stations, and approximate dwell 
time at each station. This variable also includes operational costs, which are combined with travel time, because both are based on the length and directness of the corridor. Operational costs and travel time are functions of posted speed limits, length of each alignment, vehicle costs (assuming a 40-year lifespan), maintenance costs, and long-term labor costs. In addition, penalties were imposed on the routes, including:

- a reverse-direction travel penalty of 1.5 minutes for every 1 minute of indirect travel time;

- a sharp turn (>90 degrees) penalty of 15 seconds; and

- a deceleration, dwell, and acceleration penalty at each station of 1 minute to the overall time.

The operations score is based on the following formula:

Total weighted score $=10 /\left(\mathrm{T}_{\mathrm{t}} / \mathrm{T}_{\mathrm{ts}}\right)$

where:

$\mathrm{T}_{\mathrm{t}}$ is route total time $=\left(\mathrm{T}-\mathrm{T}_{\mathrm{s}}\right)^{2}+\mathrm{T}_{\mathrm{u}}+\mathrm{H}+(\mathrm{S} \times \mathrm{D})$.

$\mathrm{T}_{\mathrm{ts}}$ is shortest route total time.

$\mathrm{T}$ is route time $=\Sigma(\mathrm{D} \times \mathrm{R})$.

$\mathrm{T}_{\mathrm{S}}$ is shortest route time.

$\mathrm{D}$ is route segment distance.

$\mathrm{R}$ is segment speed limit.

$\mathrm{T}_{\mathrm{u}}$ is 90 -degree turn time penalty.

$\mathrm{H}$ is reverse-direction time penalty.

$\mathrm{S}$ is station time penalty.

The authors used the $\left(\mathrm{T}-\mathrm{T}_{\mathrm{s}}\right)^{2}$ statement to account for the growth in maintenance costs as a route length increases from the shortest possible route.

Each corridor option was given a trip-time score, including actual minutes and penalty minutes for reverse-direction travel and sharp turns. The operations score was generated by compiling the respective time distances for all routes, and then rating the result on a percentage scale. 


\section{Right-of-Way Costs (14\% Weight)}

Right-of-way includes roadway, sidewalks, and generally all land between the sidewalk and property line. For this BRT system, the ideal right-of-way (106 feet) would include a 9-foot sidewalk with street trees, a 5-foot bike lane, two 12foot auto travel lanes, and a 12-foot BRT lane with 2-foot buffers (Figure 4). To find the right-of-way score, a 106-foot right-of-way was assumed for all the routes, with the exception of the Springwater route. The scores represent the costs of purchasing land or obtaining easements from property owners to expand the right-of-way and the political cost, which includes consideration of:

- resistance to growth, development, and loss of urban or rural aesthetics;

- resistance to building demolition, specifically historic or community structures and parks;

- need to maintain existing auto- and bicycle-lane capacity and sidewalks; and

- need to minimize negative changes to traffic patterns.

The right-of-way score was calculated by compiling the qualitatively estimated costs of land and political feasibility for the routes, then rating the result on a percentage scale.

\section{Environmental Impacts (Weight 8\%)}

This criterion refers to the natural environment (creeks and wetlands in the Pleasant Valley/Damascus area, and hillside cuts on Foster), and also to pedestrian safety mitigation measures. The chosen corridor should enable any negative impacts on either one to be mitigated at a relatively affordable cost. As there is little variation in negative pedestrian impacts among these corridor options, and the environmentally-sensitive areas are located in only a few places, it was determined that this criterion did not require substantial weighting. The environmental score was calculated by qualitatively estimating the costs of environmental and pedestrian mitigation for the routes. For each alignment, the analysis qualitatively assessed:

- possible harm to the natural environment that must be mitigated;

- estimated mitigation costs; and 
- methods for minimizing negative impacts to the pedestrian environment (e.g., providing wide sidewalks, good signing, striping and lighting, pedestrian refuge islands at crossings, and attractive and safe system access).

\section{Construction Costs (Weight 4\%)}

Infrastructure costs include roadway reconstruction (earthwork, paving, and striping), drainage, sidewalks, stations, signals, lighting, ITS enhancements, guideway if used, BRT lane pavement, and landscaping. Costs associated with acquiring land for right-of-way expansion are not included.

\section{Results}

In an analysis of six routes within the study corridor, the Powell/Interstate 205/Foster alignment was the best alternative, with a final score of 82 percent of the maximum weighted score of $100 \%$. (Table 1 summarizes the overall results of the multivariate analysis.) This route, which is 15.8 miles in length, will serve the Transit Mall and Union Station in downtown Portland and cross the Willamette River on the Hawthorne Bridge. The route travels east on Powell Boulevard to Interstate 205, where it travels south to Foster Road within the Interstate corridor, and continues on Foster Road to the future Damascus Town Center. It is a relatively direct route to the Pleasant Valley/Damascus area and traverses dense population areas and activity centers where ridership would be strong.

Overall, the Powell/Interstate 205/Foster alignment was judged to be superior in this analysis because of its directness and connectivity to regional and employment centers. Residential densities along Powell Boulevard provide adequate ridership for current bus routes that use this arterial, and projected population will further increase ridership. This route's connections to activity centers are better than those of the Powell/Foster alternative, and its use of a portion of the Interstate 205 right-of-way will allow the system to be more rapid. Its route along Powell will have a wide right-of-way and will not be constrained by the densely built-up areas on Foster Road between Southeast 50th and Interstate 205.

Because of its advantages in right-of-way width, construction and acquisition costs will be somewhat minimized. For example, Interstate 205 was originally constructed to accommodate a busway and includes a tunnel that crosses under from the northbound lanes to the southbound lanes, suggesting 
that a high-capacity transit system was intended here. Due to future population and employment growth in the area, Foster Road likely will need to be expanded to create access for residents. The entrance to Pleasant Valley is hindered by a natural bottleneck in the surrounding topography, located at the intersection of Southeast Foster and Jenne Road. Negative environmental impacts could potentially occur at this location, as well as further into the valley itself.

\section{Station Analysis}

Optimal locations for future BRT stations were analyzed based on the following criteria:

- Speed: Stations should be located near large intersections where speed will be reduced and should be at least one mile apart.

- Right-of-way: Accommodate station platform while maintaining existing infrastructure.

- Environmental and Pedestrian: Must allow for safe and convenient boarding.

- Ridership: Near intersections of major arterials and major transit corridors.

- Land Use: Near high-density, mixed-use areas; conducive to transit-oriented redevelopment; outer stations should accommodate park-and-ride facilities.

- Connectivity: Near government and educational institutions; supported by adequate commercial development; access to employment and industrial uses.

Based on the station analysis criteria, optimal station locations were determined for the highest scoring alignment. Table 2 shows the rating scale used for the Powell/Interstate 205/Foster Road alignment stations.

\section{Conclusions}

While the mean score for all six alternatives examined was 73.5 percent, the Powell/Interstate 205/Foster alignment scored 82 percent since it includes a direct route with good local ridership potential. Although the Powell/Interstate 
Journal of Public Transportation, Vol.5, No. 2, 2002

\begin{tabular}{|c|c|c|c|}
\hline 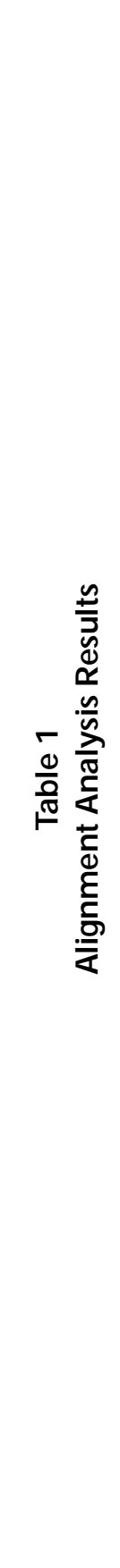 & 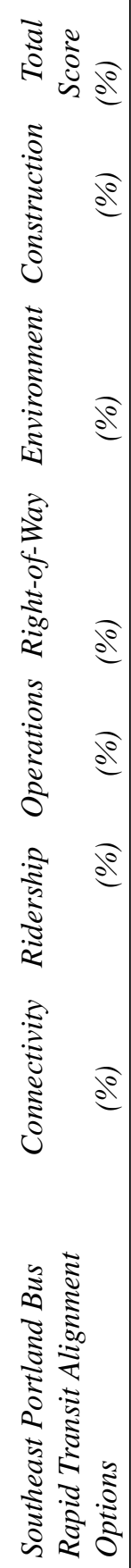 & 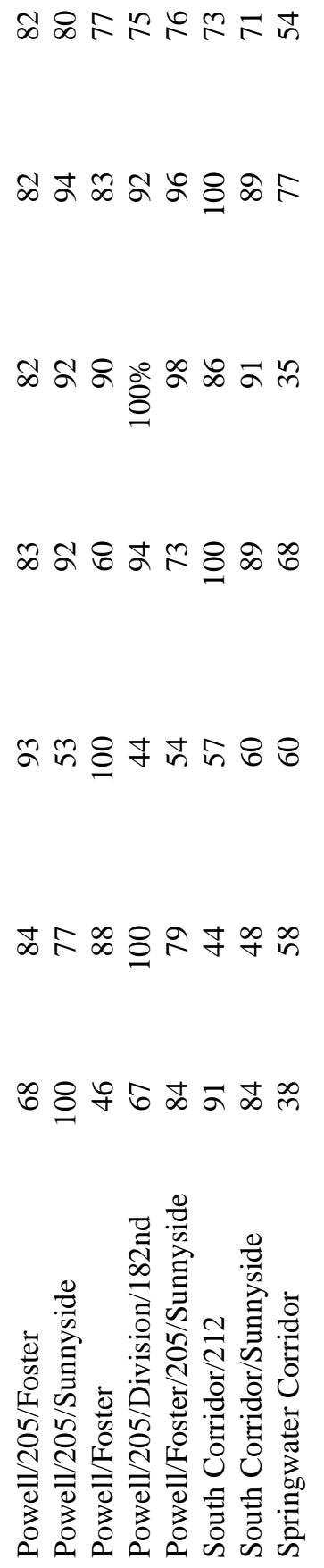 & 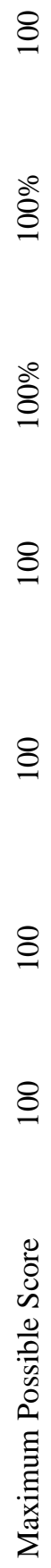 \\
\hline
\end{tabular}




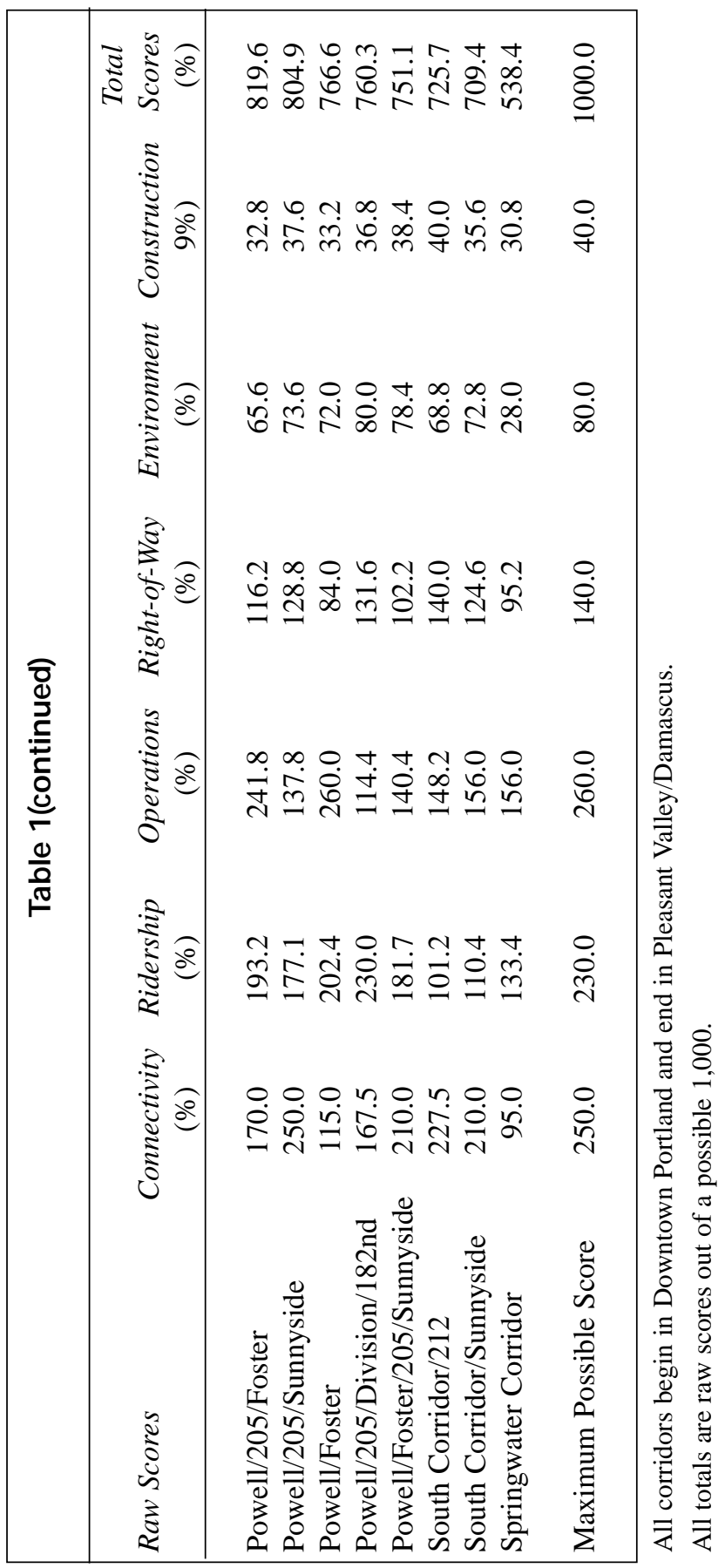




\begin{tabular}{|c|c|c|c|}
\hline \multirow{6}{*}{ 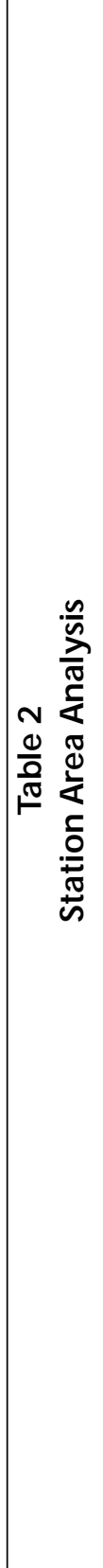 } & 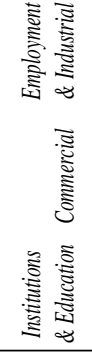 & $\begin{array}{l}\text { 衰 } \\
\text { 产 }\end{array}$ & 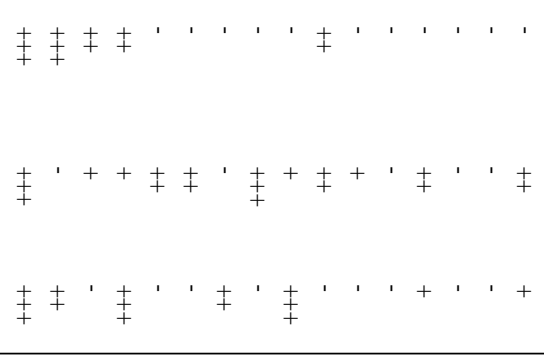 \\
\hline & 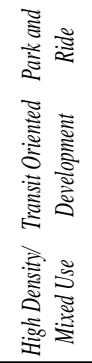 & 总 & 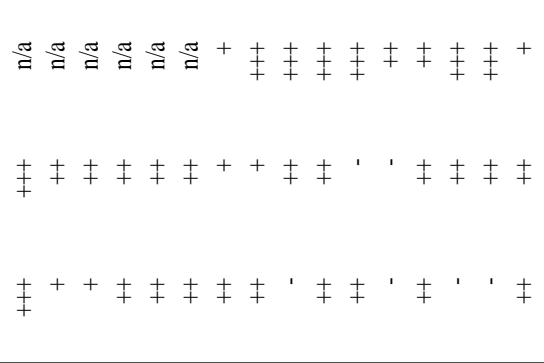 \\
\hline & 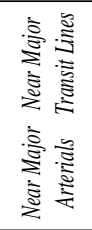 & 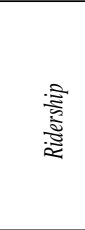 & 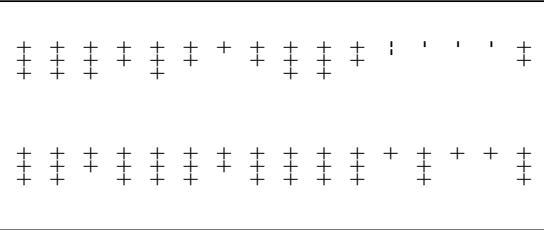 \\
\hline & 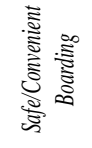 & 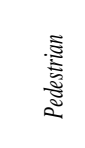 & 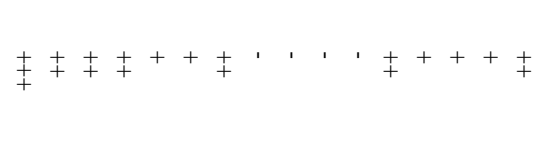 \\
\hline & 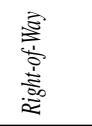 & 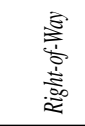 & 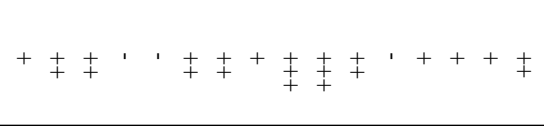 \\
\hline & 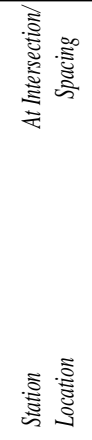 & 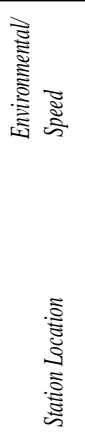 & 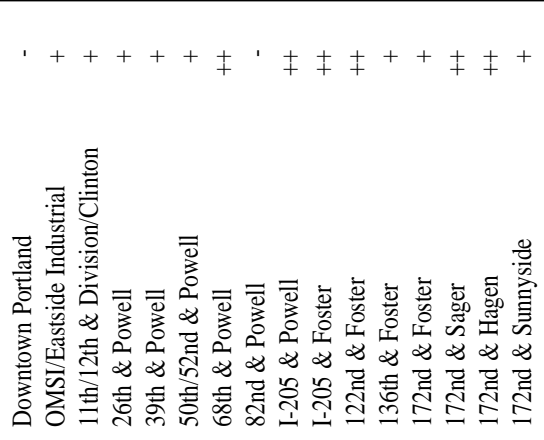 \\
\hline
\end{tabular}


205/Foster alignment did not score the highest on any single criterion, it did score very well on most. Expanding Southeast Foster Road at 162nd and Jenne Road to four travel lanes will be very expensive due to high costs of either cutting into the steep hillside to widen Foster or tunneling underneath the ridge. Though plans to widen Foster at this section are presented in Metro's RTP, the additional costs of widening this by two additional lanes for BRT are potentially prohibitive. The lowest score for this alignment was 68 percent for connectivity. Although it is a short and direct route and has a high ridership score, there is not as high a number of commercial centers and other activity locations as the second best option, Powell/Interstate 205/Sunnyside.

\section{Model Limitations}

The model used for this analysis is not without its limitations. The connectivity and ridership variables together made up nearly half of the combined weight of the six criteria. A sensitivity analysis that included varying the weights for these criteria would likely result in a different final score for the Powell/Interstate 205/Sunnyside corridor, for example. Given that this was a preliminary analysis, only basic ridership statistics were included, and only projected ridership of those living within a quarter mile of the corridor was considered. The analysis did not include the influence of feeder bus routes bringing riders to the BRT corridor (though feeder service would be paramount to the success of this system); parkand-ride lots, which can have an extensive coverage area; and riders who walk or bike to a BRT station from more than a quarter mile away.

\section{Recommendations}

A fully implemented BRT system should include frequent service, with a maximum of 30-minute headways, and 10- to 15-minute headways during peak hours. The system should have a full-service day, from early morning commutes to late night service. Vehicles should be articulated and designed for level boarding to allow for easy accessibility for all passengers, including those who require extra time to board, such as the elderly, people with disabilities, and users with sight impairments. Wide doors should be included on both sides of the vehicle to allow quick and obstacle-free access. Vehicles and station platforms should have real-time audio and visual information systems to alert 
passengers of departure and arrival times. Stations should be fully enclosed where possible, to act as a shield from both inclement weather and general traffic impacts. Stations should be equipped with amenities such as preboard payment machines, real-time bus information, benches, and trash receptacles.

\section{Implementation Strategy}

The Powell/Interstate 205/Foster PDM system should be built incrementally. Since BRT utilizes existing roadways, it can be implemented initially with minor improvements, and then other infrastructure can be added as demand increases and funding becomes available. A fleet of articulated vehicles that are distinct from other vehicles in the system should be purchased for the BRT line to give it its own identity prototype vehicle design is shown in Figures 2 and 3). Ultimately, vehicles would closely resemble those currently manufactured by Civis. Stations should be constructed in sections where median BRT lanes are added. The first sections of dedicated lanes will most likely be built in the middle of the route, around Powell and Interstate 205. Outer segments will be developed in the future, as demand increases in those areas and roadway capacity increases. The innermost sections are relatively dense and present additional physical challenges, such as negotiating with railroads to share right-of-way; which Willamette River bridge it will use; and the obvious need to acquire property to provide adequate right-of-way for the system. In the meantime, even a separated, dedicated lane from Southeast 50th and Powell to Southeast 122nd and Foster could dramatically reduce travel time in this corridor.

Ideally, there would be a complete system of dedicated median BRT lanes from the Hawthorne Bridge to Damascus Town Center by 2020. Due to right-ofway limitations, the completed infrastructure may necessitate single-lane operation or operation in mixed-traffic lanes in limited sections. These include sections of Powell where there are parks or buildings at the edge of the right-ofway, and on Foster at the 162nd Avenue bottleneck.

Despite these limitations, a rapid, compelling, limited-stop BRT service can be implemented in this corridor that would be competitive with peak-hour automobile trips, as well as a pleasant way to travel around the region. Installing a guidance system, in addition to using dedicated lanes, can further enhance the 
service by making it more convenient and attractive to potential riders. The combination of these amenities holds great promise for improving transit service and making it an appealing alternative to the automobile at a very affordable cost.

\section{Acknowledgements}

Our study team was assisted by Professors Kate Hunter-Zaworski, Annette Von Jouanne, and Alan Wallace of Oregon State University; Professor James Strathman of Portland State University; Adrian Wallace of the Portland Art Institute; and Graham Carey of Lane Transit District. Conrad Wagner and Dan Sturges provided valuable feedback. Alan Lehto of Tri-Met was our project client. The advisory team was comprised of Tom Kloster and Kim White of Metro. The Planning Workshop Faculty included Deborah Howe, Connie Ozawa, and Tom Sanchez of Portland State University.

Some of the ideas and images contained in this article were submitted as part of an entry for the Bus Rapid Transit and the American Community National Planning and Design Competition sponsored by WestStart and the Federal Transit Administration. We would like to thank Fred Silver of WestStart for his support and encouragement.

\section{References}

Briggs, Kara. April 14, 1999. Urban creek holds good news: Salmon. The Oregonian.

Clackamas County Long Range Planning, Department of Transportation and Development. November, 2000. Damascus concept planning study.

Federal Transit Administration (FTA) Office of Research, Demonstration and Innovation. 2000. Issues in bus-rapid transit.

Giannopoulos, G. 1989. Bus planning and operation in urban areas: A practical guide.

Gilmore Research Group. November 2000. Tri-Met attitude and awareness survey.

Golias, Ronan. May/June 1997. Between bus and tramway. UTI: 31-34.

Gresham, City of, Long Range Planning Team. 1999. Current socioeconomic trends in the City of Gresham: 1. 
Haywood, Howard M. October 1999. Massachusetts Bay Transportation Authority Bus-Rapid Transit Silver Line.

Henke, Cliff. January/February 1998. Cities eye busways-again. Metro Magazine: 35-40.

Lane Transit District. 1999. Lane Transit District pilot East-West BusRapid Transit corridor.

Lane Transit District. November, 2000. Lane Transit District Bus-Rapid Transit, Draft Environmental Assessment.

Metro. July 1994. Region 2040, Decisions for tomorrow, transportation analysis of the growth concept.

Metro. 2000. Regional land information system (RLIS). Portland, Oregon.

Mortenson, Eric. February 8, 2001. Sides gather together to shape new Pleasant Valley. The Oregonian.

Patton, Carl V. et al. 1993. Basic methods of policy analysis and planning. Englewood Cliffs, NJ: Prentice Hall.

Pleasant Valley Concept Plan. March/April 2001. Public Comment Report, Community Forums 1 \& 2 .

Reed, Earl. March 2001. Portland Office of Transportation (informal interview).

Scannell, Ed. May 12, 2000. Los Angeles takes first step toward Bus-Rapid Transit. The Urban Transportation Monitor: 1.

Schwarz, Marcy and Constance Eichhorn. 1996. Collaborative decisionmaking: use of multiattribute utility analysis to involve stakeholders in resolving controversial transportation issues.

Shen, L. David, et al. December. 1998. At-grade busway planning guide. Center for Urban Transportation Research, Florida International University. www.cutr.eng.usf.edu/research/nuti/busway/Busway.htm

Sneller, Joe. September/October 1997. Buses that run on rails. Mass Transit: 50-55.

South Corridor Study, Transportation Alternatives. October 16, 2000. Draft South Corridor evaluation summary.

South/North Corridor Project. April 1999. Supplemental draft Environmental Impact Statement. 
Transportation Research Board. National Academy Press. 1996. TCRP Report 19, guidelines for the location and design of bus stops. Washington, DC.

Tri-Met. 2000. five-year intelligent transportation system plan.

Tri-Met. Mar 2001. Unpublished ridership numbers for 2000 received from project client.

WestStart. February 8, 2001. Bus-Rapid Transit and the American community, a national planning and design competition.

\section{About the Authors}

MatThew Pahs (Matthew.Pahs@dot.state.mn.us) is a graduate of the Master of Urban and Regional Planning program at Portland State University. He is currently a planner for the Minnesota Department of Transportation.

MARK ROHDEN (markohden@myexcel.com) is a graduate of the Master of Urban and Regional Planning program at Portland State University. He is currently a planner for Tri-Met.

DAVID Hampsten (David.Hampsten@pdxtrans.org) is a graduate of the Master of Urban and Regional Planning program at Portland State University, with specializations in land use, transportation, and urban design. He is currently a cartographer/GIS mapper for the City of Portland, Oregon Office of Transportation

SETH GallaNT (sethgallant@hotmail.com) is a graduate of the Master of Urban and Regional Planning program at Portland State University. He is currently working with a transit advocacy group on expanding Portland's MAX light rail system.

RoBerT BerTinI (bertini@pds.edu) obtained his Ph.D. in transportation engineering at the University of California at Berkeley. He is an assistant professor of civil and environmental engineering and a research associate in the Center for Urban Studies at Portland State University. 